\title{
The modifying role of physical activity in the cross-sectional and longitudinal association of health-related quality of life with physiological functioning-based latent classes and metabolic syndrome
}

\author{
Paco Cerletti ${ }^{1,2}$, Dirk Keidel ${ }^{1,2}$, Medea Imboden ${ }^{1,2}$, Christian Schindler ${ }^{1,2}$ and Nicole Probst-Hensch ${ }^{1,2^{*}}$ (D)
}

\begin{abstract}
Background: Single cardio-metabolic risk factors are each known modifiable risk factors for adverse health and quality of life outcomes. Yet, evidence on the clustered effect of these parameters and the metabolic syndrome (MetS) on health-related quality of life (HRQoL) is still limited and mostly cross-sectional. The objectives of this study were to identify clusters of cardio-metabolic physiological functioning, to assess their associations with HRQoL in comparison with the MetS, to elucidate the modifying role of physical activity, and to assess differences in health service utilization.
\end{abstract}

Methods: This study is based on longitudinal data from two time points (2010/11 \& 2017/18) of the Swiss Study on Air Pollution and Lung and Heart Diseases (SAPALDIA). Latent class analysis (LCA) grouped participants based on a priori selected cardio-metabolic and MetS related physiological functioning variables (Body mass index, body fat, glycated hemoglobin, blood triglycerides, blood pressure). The 36-item Short-Form Health Survey (SF-36) was used to assess HRQoL. Quantile regressions were performed with and without adjustment for physical activity, to detect independent associations of the latent classes, MetS and physical activity with HRQoL. To assess the modifying role of physical activity, we additionally grouped participants based on the combination of physical activity and latent classes or MetS, respectively. Logistic regressions were used to investigate health service utilization as outcome.

Results: The LCA resulted in three classes labeled "Healthy" (30\% of participants in 2017/18), "At risk" and "Unhealthy" (29\%). The Unhealthy class scored lowest in all physical component scores of HRQoL. Compared to healthy and active participants, inactive participants in the "Unhealthy" class showed lower scores in the physical functioning domain both cross-sectionally $(-9.10(-12.02 ;-6.18))$ and longitudinally. This group had an odds ratio of $2.69(1.52 ; 4.74)$ for being hospitalized in the previous 12 months.

* Correspondence: nicole.probst@swisstph.ch

'Swiss Tropical and Public Health Institute, Socinstrasse 57, 4051 Basel, CH, Switzerland

${ }^{2}$ University of Basel, Petersplatz 1, 4001 Basel, CH, Switzerland

(c) The Author(s). 2020 Open Access This article is licensed under a Creative Commons Attribution 4.0 International License, which permits use, sharing, adaptation, distribution and reproduction in any medium or format, as long as you give appropriate credit to the original author(s) and the source, provide a link to the Creative Commons licence, and indicate if changes were made. The images or other third party material in this article are included in the article's Creative Commons licence, unless indicated otherwise in a credit line to the material. If material is not included in the article's Creative Commons licence and your intended use is not permitted by statutory regulation or exceeds the permitted use, you will need to obtain permission directly from the copyright holder. To view a copy of this licence, visit http://creativecommons.org/licenses/by/4.0/ The Creative Commons Public Domain Dedication waiver (http://creativecommons.org/publicdomain/zero/1.0/) applies to the data made available in this article, unless otherwise stated in a credit line to the data. 
(Continued from previous page)

Conclusions: These results point to subjects with adverse cardio-metabolic physiological functioning and low activity levels as an important target group for health promotion and maintenance of well-being. The promotion of physical activity at the early stages of aging seems pivotal to mitigate the impact of the MetS on HRQL at higher age.

Keywords: Latent class analysis, Aging, Lifestyle, Physical activity, Cardio-metabolic, Metabolic syndrome, Physiological functioning, Health-related quality of life

\section{Introduction}

In the Western world, the proportion of people aged 80 years and above is estimated to double by 2080 compared to 2014 [1]. At older age disability adjusted life years and years lived with disabilities are increasing considerably $[2,3]$. At the same time reduced quality of life (QoL) has been associated with older age $[4,5]$. This emphasizes the global importance in investing into healthy aging and the maintenance of QoL. The concept of QoL is characterized by high complexity involving as well as influencing several life domains. In the last decades, the notion of health-related quality of life (HRQoL) has emerged [6] and is on the individual level an expression of physical and mental health perceptions.

Previous studies have commonly investigated effects of lifestyle and physiological functioning parameters on HRQoL domains one factor at a time. Yet, the simultaneous examination of these risk factors, such as combinations of cardio-metabolic physiological functioning and physical activity, provides valuable insights for possible improvements in population health and HRQoL $[7,8]$. With advancing age, the physiology of numerous organ systems changes significantly. These continuous alterations lead to a decrease in several functions. The most often observed changes are increasing body fat and loss of muscle mass that commonly result in physical inactivity and vice versa [9].

A clustering approach is frequently used to examine the possible synergy of several factors and to give insights on important underlying patterns, e.g. related to physiological functioning. Several clustering methods (model and non-model-based) are available for this purpose. Latent Class Analysis (LCA) is a model-based approach that attempts to detect homogeneous groups within a heterogeneous population. It is a sophisticated tool to capture the complexity of interrelated risk factors [10]. Three recent studies and one systematic-review looked at the association of lifestyle behaviors and physiological functioning with HRQoL domains [7, 11, 12].

Furthermore, the metabolic syndrome (MetS) is a good example for the importance of investigating effects of multiple predictors with one health outcome. In particular, components of the metabolic syndrome, i.e. central obesity, hyperglycemia, dyslipidemia, and hypertension, and thus lifestyle factors related to the MetS are prevalent early warning signs in aging populations and increase the risk of a range of common chronic cerebrovascular, cardiovascular, and neurological disorders known to be associated with severe disability [13]. As shown in a systematic review, the MetS points towards worsening HRQoL, even though evidence is still limited and primarily derived from cross-sectional studies [14].

Whether physical activity can rescue persons with MetS from poor quality of life remains poorly understood with some limited suggestive evidence [15-17]. But physical inactivity has in itself been associated with both, poor HRQoL and cardiovascular morbidity. According to a UK biobank study, physical inactivity significantly increased the all-cause mortality and cardiovascular disease mortality in middle- to old- aged subjects [18], which was also seen in a study of the Kadoorie biobank [19]. Besides its direct effects on cardiovascular phenotypes such as hypertension, physical activity may additionally lower the need for medication and thereby prevent well-known side effects, which often affect HRQoL [20]. Especially in older adults physical activity can thus have major benefits for HRQoL [21].

However, none of the mentioned studies looked at the association of the identified clusters in combination with physical activity status with HRQoL domains in a longitudinal population-based setting with nation-wide coverage. Consequently, there is a research gap in assessing the linked patterns of cardio-metabolic physiological factors and physical activity - being the most prevalent lifestyle variable - with associations of HRQoL.

To enhance the understanding of joint cross-sectional and longitudinal associations of physiological functioning and physical activity with HRQoL in the general population, the objectives of this study were (1) to identify common latent classes of physiological functioning related to cardio-metabolic health in the Swiss Study on Air Pollution and Lung and Heart Diseases (SAPALDIA ), (2) to assess associations of the identified latent classes with HRQoL and compare them to MetS-HRQoL associations, (3) to identify possible protective influences of physical activity in these associations and finally (4) to 
elucidate differences in health service utilization between the latent classes and persons with and without MetS.

\section{Methods}

\section{Study population}

SAPALDIA is a population-based cohort with associated biobank initiated in 1991. In SAPALDIA1, 9'651 adults (18-62 years) were randomly recruited from eight study areas in Switzerland representing the country's geographic and cultural diversity [22]. In the subsequent decades, two follow-ups were carried out including 8'047 subjects in SAPALDIA2 (2001/2002) and 6'088 in SAPA LDIA3 (2010/2011) [23]. All three assessments comprised questionnaires (based on validated instruments as for example IPAQ for physical activity) and health examinations of increasing complexity over time.

The current research is based on the subsample of participants of the third follow-up (SAPALDIA4, 2017/ 18 , who were aged 55 years and older at the time. Unlike previous SAPALDIA surveys, data collection in SAPALDIA4 was primarily questionnaire based. Only SAPALDIA participants who were aged 55 years and older and who had answered all SAPALDIA4 questionnaires were subsequently invited for a health assessment (SAPALDIA55+) to one of the eight local study centers (Aarau, Basel, Davos, Geneva, Lugano, Montana, Payerne and Wald). The SAPALDIA55+ health visit focused on the collection of healthy aging related determinants and preclinical aging endpoints. SAPALDIA4 involved a total of 5'149 participants answering multiple selfadministered questionnaires. The subgroup of participants aged 55 years and older who underwent a health examination and answered additional age-related questions consisted of $n=1^{\prime} 746$ participants. While crosssectional analyses were restricted to SAPALDIA4 participants $55+$, we used data of the same subjects from the prior follow-up (SAPALDIA3) to assess longitudinal associations.

The present analysis ultimately involved 1'124 of the SAPALDIA4 55+ participants who provided complete information on all relevant variables. For 902 of these subjects complete information was also available from their SAPALDIA3 assessment for longitudinal analyses (Fig. 1). To assess bias due to loss-of-follow-up, the baseline characteristics at SAPALDIA1 of participants who reached the age of $55+$ at the time of the health assessments, stratified by participation status at SAPA LDIA4 55+ examination, can be seen in Additional Table 1.

The SAPALDIA cohort study complies with the Declaration of Helsinki. For each survey, ethics approval was granted by the regional ethics committees and participants provided written informed consent prior to participation.

\section{Questionnaire derived information}

For SAPALDIA4, cohort participants were invited to answer multiple self-administered questionnaires on paper or online. The questionnaires consisted of information on socio-demographic characteristics, lifestyle, psychosocial factors, disease symptoms, diagnoses, medications, as well as health and social service use. The SAPALDIA $455+$ assessment additionally included a questionnaire specifically addressing aging-related determinants and risk factors.

In contrast to the self-administration of SAPALDIA4 questionnaires, SAPALDIA3 questionnaires were applied in the context of in-person interviews. Relevant questionnaire information for this analysis were questions on physical activity levels (frequency of moderate and vigorous physical activity according to WHO guidelines) as well as the covariates: sex, age, and education level (Low $=$ Primary School $(\leq 9$ years $)$, Middle $=$ Secondary school, middle school or apprenticeship ( $\leq 12$ years), High $=$ Technical College or University $(\geq 12$ years $))$. We chose for this population, education levels as a proxy for socio-economic status, as this measure has proven in previous studies to well represent the socio-economic status [24].

We further used information on health service utilization as secondary endpoint - next to HRQoL -, which was also assessed in the SAPALDIA4 questionnaire. We defined three health care utilization variables: Visit to physician(s); to hospital(s); combination of visits to physician(s) and hospital(s). The information were reported for the 12 months preceding the survey (yes vs. no for each). We treated these response variables as binary because nearly all participants reported 0 or 1 visit in the specified period.

Furthermore, we used information on doctor's diagnosis reported in the SAPALDIA4 questionnaires for sensitivity analysis. Specifically, we defined a variable capturing the following cardiovascular diseases: Myocardial Infarction, Angina Pectoris, Heart Insufficiency, Claudicatio Intermittens and Stroke.

\section{Health-related quality of life (HRQoL) measures}

Questionnaires at SAPALDIA3 and SAPALDIA4 also included the 36-Item Short-Form Health Survey (SF-36), a widely used HRQoL assessment tool that was validated in large population-based surveys as well as in clinical settings $[25,26]$. The construct as well as the criteria validity and reliability were thoroughly tested in the development of this tool and are therefore given [27, 28].

The questionnaire is designed to provide a summary of physical and mental health scores, based on eight domains. The physical component comprises physical functioning $(\mathrm{PF})$, bodily pain $(\mathrm{BP})$, role-physical (RP) and general health perception $(\mathrm{GH})$. The mental 


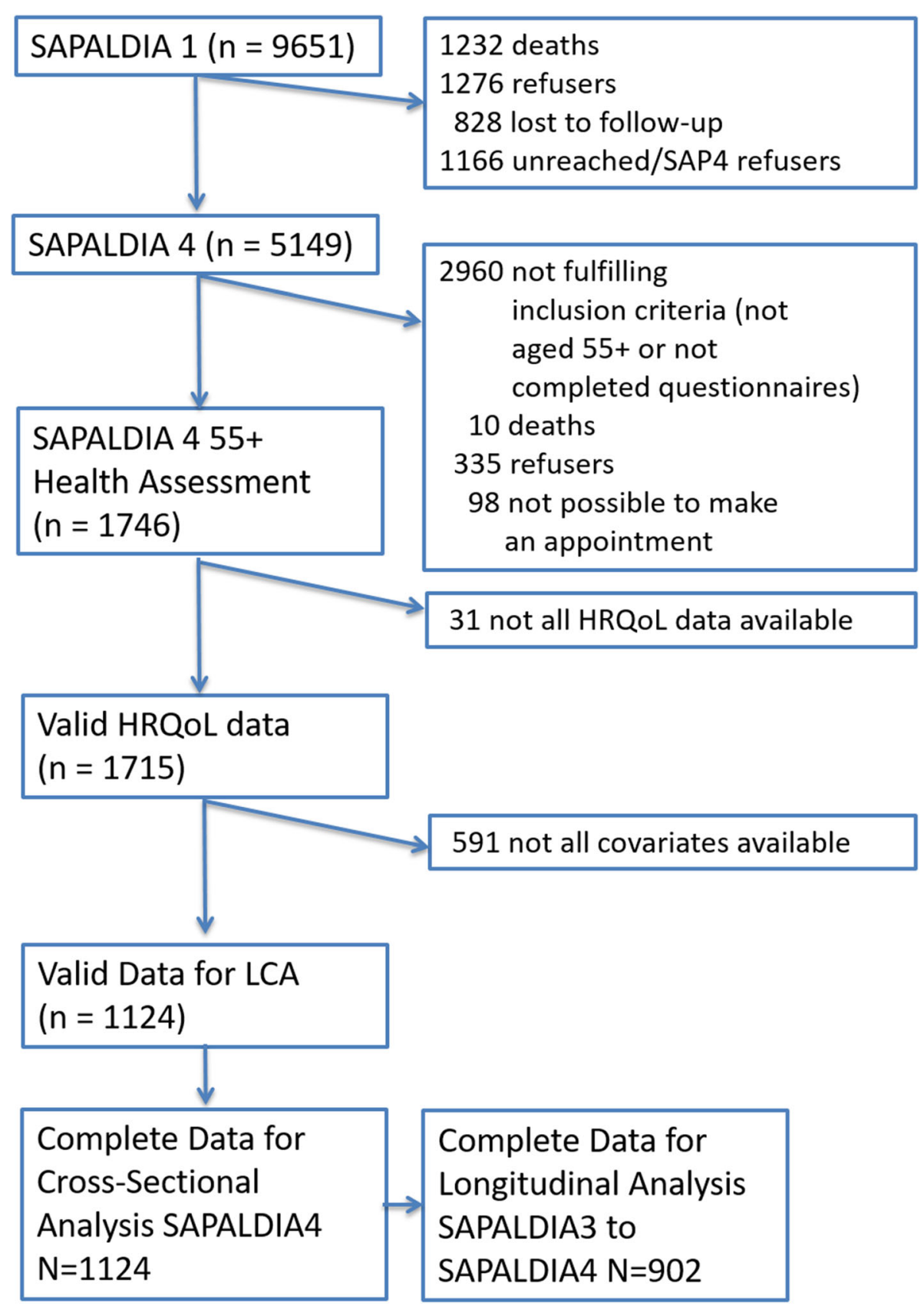

Fig. 1 Participation from SAPALDIA 1 to the current study (1991-2018)

component reflects the vitality (VT), social role functioning (SF), role emotional (RE) and mental health perception (MH). Scores for each subscale range from 0 to 100, and higher scores indicate better HRQoL [29]. Three domains of the SF-36 (social role functioning, role-physical \& role emotional) showed only very few distinct values in our sample and the proportion of subjects at SAPALDIA4 with the perfect score 100 ranged from 72 to $85 \%$. As a consequence, we did not consider these variables. As these variables represent minor sub- scales of the SF-36, their exclusion still allowed us to assess MCS and PCS as HRQoL outcomes.

\section{Health examination}

The health examination consisted of measurements of weight (SECA877 flat scale; SAPALDIA3\&4), height (SECA206, wall-fixed measuring system; SAPALDIA 3\&4), hip and waist circumference (SECA201 ergonomic measuring tape, SECA, Reinach, Switzerland; SAPA LDIA3\&4), bio-impedance analysis (BIA) using two 
different devices (Helios, Forana GmbH, Frankfurt, Germany (SAPALDIA3\&4 Tanita MC-780MA, TANI TACorporation, Tokyo, Japan; SAPALDIA4), blood pressure and heart rate measurements (Omron MC6 or Omron 705-IT, Anandic Medical Systems AG, Bern Switzerland; SAPALDIA3\&4); non-fasting blood glucose (only measured at SAPALDIA3); diagnostics for HbA1c and triglycerides (SAPALDIA4: point-of-care diagnostics from capillary blood: Afinion AS100 Analyzer; ALERE, Wädenswil, Switzerland; SAPALDIA3: analysis of venous blood) [30, 31].

Blood pressure measurements at SAPALDIA3\&4 were taken after the participant was seated for at least $10 \mathrm{~min}$. Two measurements were taken, with a break of $3 \mathrm{~min}$ between measurements. The blood measurements for glycemia and triglycerides were taken in a non-fasting state. From the anthropometric measurements, body mass index (BMI) (SAPALDIA3\&4) and waist to hip ratio (SAPALDIA3 \& 4) were derived.

\section{Cardio-metabolic physiological functioning clustered in latent classes}

Five categorical variables at SAPALDIA3\&4, which reflect cardio-metabolic physiological functioning were considered for identifying latent classes. At both time points (SAPALDIA3 \& 4) variables with evidence-based thresholds or recommendations were categorized accordingly, namely systolic blood pressure [32] (diastolic blood pressure was omitted due to its high correlation with systolic blood pressure), BMI [33], HbA1c [34] and triglycerides [35]. For percentage body fat, sex-specific tertiles were calculated in the absence of a reference for categorization (Table 1).

\section{Metabolic syndrome}

The metabolic syndrome at SAPALDIA3\& 4 was defined based on the Joint Interim Statement (JIS) [36]. The JIS defines the metabolic syndrome if any three of the following values are present: Blood glucose $\geq 5.6 \mathrm{mmol} / \mathrm{L}$ (medication or diagnosis for elevated blood glucose as alternate indicator); waist circumference $\geq 94 \mathrm{~cm}$ in men $\& \geq 80 \mathrm{~cm}$ in women; systolic blood pressure $\geq 130$ or diastolic blood pressure $\geq 85$ (antihypertensive medication or diagnosis as alternate indicator); hdl $<1.0$ $\mathrm{mmol} / \mathrm{L}$ in men $\&<1.3 \mathrm{mmol} / \mathrm{L}$ in women; triglycerides $\geq 1.7 \mathrm{mmol} / \mathrm{L}$ (medication or diagnosis for dyslipidemia as alternate indicator). At SAPALDIA4 we used Hba1C instead of blood glucose ( $\mathrm{Hba} 1 \mathrm{C} \geq 5.7 \%$, medication or diagnosis for elevated blood glucose as alternate indicator), as blood glucose was not measured in this followup.

\section{Statistical analysis}

In a first step [1] LCA was carried out to empirically classify cardio-metabolic physiological functioning variables, separately for SAPALDIA3 and SAPALDIA4. Subjects were characterized based on their values of the five predictor variables. LCA was used as an explorative tool (unconstrained LCA) without a priori expectation about the number of classes.

In order to detect the appropriate number of classes and maximize model fit, we started with a one-class model and increased the number of latent classes up to six. The final model was selected by examining the Bayesian information criterion (BIC) and the Akaike Information Criterion (AIC) in the first place. These indices have shown to be useful for determining the appropriate number of classes for LCA [37]. We checked whether there was a good discrimination between the final definition of latent classes and the five predictor variables. Two additional model fit indices, the adjusted $\mathrm{BIC}$ and the consistent AIC, were considered along with the proportions of the single classes to further support the decision on the final model. We assessed crosssectional associations of the derived latent classes at SAPALDIA4 with socio-demographic characteristics of the study population by using multinomial logistic regression models with latent class membership as outcome variable and sex, age, educational level and study area as simultaneous predictor variables.

To assess cross-sectional and longitudinal associations of the latent classes with HRQoL domains and to compare them to according MetS-HRQoL associations, we performed quantile regression models with adjustment for individual predictor variables (e.g. sex, age and educational level) as well as for HRQoL at baseline in the

Table 1 Categorization of physiological functioning variables for LCA at SAPALDIA3 \& 4

\begin{tabular}{ll}
\hline Variables & Categorization for LCA \\
\hline Systolic blood pressure & $\leq 120-129$ (normal), 130-139 (elevated), $\geq 140$ (hypertensive) \\
BMI & $<18.5$ (underweight), 20- $<25$ (normal weight), $\geq 25-30$ (overweight), $>30$ (obese) \\
HbA1c (\%) & $<5.7$ (desirable), 5.7-6.5(borderline), $>6.5$ (high) \\
Triglycerides (mmol/l) & $<1.7$ (desirable), 1.7-2.0 (borderline), > 2.0 (high) \\
Percentage Body fat (\%) & Male: $<26$ (low), 26-31 (intermediate), $>31$ (high) \\
& Female: $<36$ (low), 36-40 (intermediate), $>40$ (high)
\end{tabular}


case of longitudinal associations. Quantile regression models were chosen to address the problem of leftskewed distribution of HRQoL measures.

In order to assess confounding and effect modification by physical activity in the above associations, we first ran the models with and without adjustment for physical activity and second created composite variables classifying participants based on a combination of latent classes or MetS with physical activity status.

Finally, we used logistic regression models to assess cross-sectional associations of the composite variables with health service utilization.

For sensitivity analyses we reran analyses by excluding subjects with self-reported diagnoses of a cardiovascular disease at SAPALDIA4 (Myocardial Infarction, Angina Pectoris, Heart Insufficiency, Claudicatio Intermittens, Stroke).

We performed all analyses using Stata 15 (Stata Corporation, College Station, Texas).

\section{Results}

\section{Characteristics of the study population}

The descriptive characteristics of the study population can be seen in Table 2. Women and men were equally distributed among the subjects at both time points (SAPALDIA3\&4). The mean age at SAPALDIA3 was $60.0 \pm 7.8$ (range: $47-80$ years) and at SAPALDIA4 $67.4 \pm 7.9$ (range: $55-88$ years). Nearly two-third of the subjects showed medium education levels, which refers to having completed middle school. The mean score of the overall HRQoL domain $(\mathrm{GH})$ showed descriptive difference by sex and with advancing age. With declining education the score decreased. The HRQoL GH scores mostly decreased in a dose-dependent manner with increasingly poorer physiological functioning variables (blood pressure, glycemia, body fat, BMI and triglycerides). Physical activity displayed higher HRQoL GH scores for the sufficiently active subjects. Physical activity and physiological parameters generally decreased from SAPALDIA3 to SAPALDIA4, and therefore with increase in age, while the prevalence of the metabolic syndrome increased.

\section{Model fit statistics for LCA}

At both time points (SAPALDIA3 \& 4) the main values of the BIC and AIC reached its minimum in the model consisting of three classes. The adjusted BIC as well as the CAIC supported these results (Additional Tables 2 \& 3). By considering these goodness-of-fit indices the model with three latent classes was chosen to be the final model. The model with three classes also generated a relatively even distribution at SAPALDIA4 $\left(\mathrm{N}_{1}=340\right.$ $\mathrm{N}_{2}=455, \mathrm{~N}_{3}=329$ ) within the study sample, which increases statistical power, while the SAPALDIA3 sample showed fewer subjects in the third class $\left(\mathrm{N}_{1}=412, \mathrm{~N}_{2}=\right.$ $352, \mathrm{~N}_{3}=137$ ).

\section{Three cardio-metabolic physiological functioning clusters defined by LCA}

The proportion of the different classes and the estimated class-specific probabilities for the predictor variables are shown in Additional Table 4 (SAPALDIA4) and Additional Table 5 (SAPALDIA3). The by-latent-class distribution of variables included in deriving the classes was comparable between SAPALDIA3 and SAPALDIA4.

Class 1, labeled "Healthy" consisted of individuals having mainly normal physiological functioning measured such as blood pressure, glycemia, triglycerides and percentage body fat or BMI. This class included $30 \%$ of participants at SAPALDIA4 and $46 \%$ of participants at SAPALDIA3.

In Class 2, labeled "At risk", most individuals were overweight and had intermediate percentages of body fat. The prevalence of high blood pressure, hyperglycemia, and dyslipidemia in this group were intermediate compared to those observed for classes 1 and 3. Most subjects at SAPALDIA4 were categorized into this class (42\%), while at SAPALDIA3 this class consisted of $29 \%$ of the participants.

Class 3, labeled "Unhealthy" had an overrepresentation of individuals that were obese, in contrast to the other classes that contained no obese participants. Accordingly, participants in class 3 were more likely to have a high percentage of body fat, to be hypertensive, to have high glycemia and triglyceride values. In the SAPALDIA 4 sample $29 \%$ was assigned to this class, while in the SAPADALDIA3 sample only $15 \%$.

In regards to the socio-demographic distribution of the latent classes at SAPALDIA4 (Table 3) we observed that females were less likely to belong to the Unhealthy or the At risk class. The likelihood of being categorized as "Healthy" decreased with age and lower educational level. Persons aged $75+$ or with low educational level were particularly likely to be categorized as Unhealthy. The descriptive data of sex, age and education between the different classes can be seen in Additional Table 6.

\section{Cross-sectional associations of latent classes and MetS with $\mathrm{HRQ}$ oL domains, without and with additional adjustment for physical activity (SAPALDIA4)}

The results of the quantile regression analyses (Table $4 \mathrm{~A})$ showed that, compared with the reference class (Healthy) median HRQoL scores were lower in the Unhealthy class, i.e., with differences of -3.06 (95\%CI: ($5.51,-2.14)$ in the GH domain, of $-5.64(-6.98,-4.30)$ in the PF domain and of $-9.14(-13.91,-4.38)$ in the BP domain. The At risk class only had borderline significant scores in the PF domain $(-1.01(-2.05 ;-0.03))$, 
Table 2 Characteristics of the study population

\begin{tabular}{|c|c|c|c|}
\hline Variable & SAPALDIA3 $(n=902)$ & SAPALDIA4 $(n=1124)$ & Mean score of overall HRQoL (General Health) at SAPALDIA4 \\
\hline \multicolumn{4}{|l|}{ Sex } \\
\hline Male & $469(52 \%)$ & $561(50 \%)$ & 70.4 \\
\hline Female & $433(48 \%)$ & $563(50 \%)$ & 72.4 \\
\hline Age (Mean, SD) & $60.0 \pm 7.8$ & $67.4 \pm 7.9$ & 71.4 \\
\hline \multicolumn{4}{|l|}{ Education } \\
\hline Low & $22(2 \%)$ & $59(5 \%)$ & 69.4 \\
\hline Middle & $541(60 \%)$ & $705(63 \%)$ & 71.5 \\
\hline High & $339(38 \%)$ & $360(32 \%)$ & 71.5 \\
\hline \multicolumn{4}{|l|}{ Physiological functioning } \\
\hline \multicolumn{4}{|l|}{ BMI } \\
\hline Low $(<18.5)$ & $9(1 \%)$ & $11(1 \%)$ & 73.8 \\
\hline Normal $(20-<25)$ & $412(46 \%)$ & $467(42 \%)$ & 72.4 \\
\hline Overweight ( $\geq 25-30$ ) & $352(39 \%)$ & $449(40 \%)$ & 71.8 \\
\hline Obese (> 30) & $129(14 \%)$ & $197(18 \%)$ & 68.0 \\
\hline \multicolumn{4}{|l|}{ Body Fat (\%) } \\
\hline Low & 302 (33\%) & 375 (33\%) & 73.2 \\
\hline Intermediate & $300(33 \%)$ & 375 (33\%) & 72.1 \\
\hline High & $300(33 \%)$ & $374(33 \%)$ & 68.5 \\
\hline \multicolumn{4}{|l|}{ Triglycerides } \\
\hline Normal & $548(61 \%)$ & $668(59 \%)$ & 72.3 \\
\hline Borderline & 89 (10\%) & $127(11 \%)$ & 71.8 \\
\hline High & $265(29 \%)$ & $329(29 \%)$ & 69.4 \\
\hline \multicolumn{4}{|l|}{ Glycemia (HbA1c) } \\
\hline Desirable & 819 (91\%) & 775 (69\%) & 72.2 \\
\hline Borderline & $69(8 \%)$ & $297(26 \%)$ & 70.3 \\
\hline High & $14(33 \%)$ & $52(5 \%)$ & 65.5 \\
\hline \multicolumn{4}{|l|}{ Blood pressure (systolic) } \\
\hline Normal & $421 / 47 \%)$ & $446(40 \%)$ & 72.4 \\
\hline Elevated & $182(20 \%)$ & $236(21 \%)$ & 70.6 \\
\hline Hypertensive & $299(33 \%)$ & 442 (39\%) & 70.9 \\
\hline \multicolumn{4}{|c|}{ Physical Activity Guidelines (WHO) } \\
\hline Inactive & $187(21 \%)$ & $352(31 \%)$ & 67.4 \\
\hline Sufficiently active & $715(79 \%)$ & $772(69 \%)$ & 73.3 \\
\hline Prevalence of the MetS & 287 (32\%) & 499 (44\%) & \\
\hline
\end{tabular}

Education: Low = Primary School ( $\leq 9$ years), Middle = Secondary school, middle school or apprenticeship ( $\leq 12$ years), High $=$ Technical College or University ( $\geq 12$ years)

Physical Activity Guidelines (WHO)

Inactive: $<150$ min of MPA and $<75$ VPA per week

Sufficient: $>150$ min of MPA or $>75$ VPA per week

HbA1c (\%): $<5.7$ (desirable), 5.7-6.5(borderline), > 6.5 (high)

Triglycerides (mmol/l): $<1.7$ (desirable), 1.7-2.0 (borderline), $>2.0$ (high)

Percentage Body fat (\%): Male: 10-26 (low), 26-31 (intermediate), > 31 (high)

Female: 9-36(low), 36-40 (intermediate), > 40 (high)

Systolic blood pressure: 120-129 (normal), 130-139 (elevated), $\geq 140$ (hypertensive)

MetS = Metabolic Syndrome: Any three of the following values: Blood glucose $\geq 5.6 \mathrm{mmol} / \mathrm{L}$ (Hba1C $\geq 5.7$ in SAPALDIA4); waist circumference $\geq 94 \mathrm{~cm}$ in men \&

$\geq 80 \mathrm{~cm}$ in women; systolic blood pressure $\geq 130$ or diastolic blood pressure $\geq 85$; hdl $<1.0 \mathrm{mmol} / \mathrm{L}$ in men $\&<1.3 \mathrm{mmol} / \mathrm{L}$ in women; triglycerides $\geq 1.7 \mathrm{mmol} / \mathrm{L}$ 
Table 3 Association of socio-demographic characteristics with the latent classes (SAPALDIA4)

\begin{tabular}{|c|c|c|c|c|c|c|c|c|}
\hline \multirow[b]{2}{*}{ Latent Classes } & \multicolumn{2}{|l|}{ Sex } & \multicolumn{2}{|c|}{ Age (years) } & \multirow{3}{*}{$75+$} & \multicolumn{2}{|c|}{ Education } & \multirow{3}{*}{ High } \\
\hline & Male & Female & $55-64$ & $65-75$ & & Low & Middle & \\
\hline & \multicolumn{6}{|c|}{ RRR $(95 \% \mathrm{Cl})$} & & \\
\hline \multicolumn{9}{|c|}{ Healthy (Reference) } \\
\hline At risk & Ref & $0.51^{*}(0.38 ; 0.69)$ & Ref & $1.19(0.87 ; 1.63)$ & $1.59^{*}(1.04 ; 2.44)$ & Ref & $0.50(0.38 ; 1.69)$ & $0.32^{*}(0.14 ; 0.76)$ \\
\hline Unhealthy & Ref & $0.47^{*}(0.34 ; 0.66)$ & Ref & $2.02^{*}(1.43 ; 2.87)$ & $2.50^{*}(1.58 ; 3.96)$ & Ref & $0.30^{*}(0.13 ; 0.69)$ & $0.20^{*}(0.080 ; 0.48)$ \\
\hline
\end{tabular}

RRR = Relative Risk Ratio; * $=p<0.05$

Relative risk ratios are mutually adjusted for all variables included in the model as well as for study area

Table 4 Cross-sectional adjusted associations of latent classes (4A) and metabolic syndrome (4B) with HRQoL domains, without and with additional adjustment for physical activity (SAPALDIA4)

\begin{tabular}{|c|c|c|c|c|c|c|c|c|c|c|}
\hline \multirow[t]{2}{*}{$N=1124$} & \multicolumn{2}{|c|}{ General Health (GH) } & \multicolumn{2}{|l|}{$\begin{array}{l}\text { Physical } \\
\text { Functioning (PF) }\end{array}$} & \multicolumn{2}{|l|}{ Bodily Pain (BP) } & \multicolumn{2}{|l|}{ Vitality (VT) } & \multicolumn{2}{|c|}{ Mental Health (MH) } \\
\hline & $\begin{array}{l}\text { Coefficient } \\
(95 \% \mathrm{Cl})\end{array}$ & $\begin{array}{l}P- \\
\text { value }\end{array}$ & $\begin{array}{l}\text { Coefficient } \\
(95 \% \mathrm{Cl})\end{array}$ & $\begin{array}{l}\mathrm{P} \text { - } \\
\text { value }\end{array}$ & $\begin{array}{l}\text { Coefficient } \\
(95 \% \mathrm{Cl})\end{array}$ & $\begin{array}{l}\mathrm{P} \text { - } \\
\text { value }\end{array}$ & $\begin{array}{l}\text { Coefficient } \\
(95 \% \mathrm{Cl})\end{array}$ & $\begin{array}{l}\mathrm{P} \text { - } \\
\text { value }\end{array}$ & $\begin{array}{l}\text { Coefficient } \\
(95 \% \mathrm{Cl})\end{array}$ & $\begin{array}{l}\mathrm{P} \text { - } \\
\text { value }\end{array}$ \\
\hline \multicolumn{11}{|l|}{$\begin{array}{l}\text { 4A. Latent } \\
\text { classes }\end{array}$} \\
\hline Healthy & Reference & & & & & & & & & \\
\hline At risk & $\begin{array}{l}-0.22(-2.57 \\
2.14)\end{array}$ & 0.855 & $\begin{array}{l}-1.01(-2.05 ;- \\
0.03)\end{array}$ & 0.057 & $\begin{array}{l}-1.39(-4.17 \\
1.40)\end{array}$ & 0.329 & $\begin{array}{l}-0.00(-2.00 ; \\
2.00)\end{array}$ & 1.000 & $\begin{array}{l}-0.30(-1.97 ; \\
1.16)\end{array}$ & 0.721 \\
\hline Unhealthy & $\begin{array}{l}-3.06(-5.51 ;- \\
0.58)\end{array}$ & 0.015 & $\begin{array}{l}-5.64(-6.98 ;- \\
4.30)\end{array}$ & $\begin{array}{l}< \\
0.001\end{array}$ & $\begin{array}{l}-9.14(-13.91 ;- \\
4.38)\end{array}$ & $\begin{array}{l}< \\
0.001\end{array}$ & $\begin{array}{l}-2.50(-5.22 ;- \\
0.22)\end{array}$ & 0.072 & $\begin{array}{l}-1.10(-3.37 \\
1.16)\end{array}$ & 0.339 \\
\hline \multicolumn{11}{|c|}{ + Physical Activity } \\
\hline Healthy & Reference & & & & & & & & & \\
\hline At risk & $\begin{array}{l}0.12(-2.28 \\
2.52)\end{array}$ & 0.924 & $\begin{array}{l}-0.73(-1.65 \\
0.18)\end{array}$ & 0.115 & $-1.43(-4.26 ; 1.39)$ & 0.319 & $\begin{array}{l}-2.50(-4.52 ;- \\
0.48)\end{array}$ & 0.092 & $\begin{array}{l}0.00(-1.93 ; \\
1.93)\end{array}$ & 1.000 \\
\hline Unhealthy & $\begin{array}{l}-2.64(-5.29 \\
0.00)\end{array}$ & 0.050 & $\begin{array}{l}-5.00(-6.59 ;- \\
3.41)\end{array}$ & $\begin{array}{l}< \\
0.001\end{array}$ & $\begin{array}{l}-7.82(-12-48 ;- \\
3.16)\end{array}$ & 0.001 & $\begin{array}{l}-2.50(-4.76- \\
0.24)\end{array}$ & 0.030 & $\begin{array}{l}0.00(-2.46 ; \\
2.46)\end{array}$ & 1.000 \\
\hline $\begin{array}{l}\text { Physical } \\
\text { Activity } \\
\text { (Sufficiently } \\
\text { active) }\end{array}$ & $4.27(1.98 ; 6.56)$ & $\begin{array}{l}< \\
0.001\end{array}$ & $3.92(2.50 ; 5.34)$ & $\begin{array}{l}< \\
0.001\end{array}$ & $4.27(0.67 ; 7.87)$ & 0.020 & $7.50(5.28 ; 9.71)$ & $\begin{array}{l}< \\
0.001\end{array}$ & $4.00(1.50 ; 6.50)$ & 0.002 \\
\hline \multicolumn{11}{|c|}{ 4B. Metabolic Syndrome (MetS) } \\
\hline No MetS & Reference & & & & & & & & & \\
\hline Yes MetS & $\begin{array}{l}-3.47(-5.41 \\
-1.54)\end{array}$ & $\begin{array}{l}< \\
0.001\end{array}$ & $\begin{array}{l}-3.46(-4.69 ; \\
-2.22)\end{array}$ & $\begin{array}{l}< \\
0.001\end{array}$ & $\begin{array}{l}-2.69(-6.39 ; \\
1.01)\end{array}$ & 0.153 & $\begin{array}{l}-5.00(-7.18 ;- \\
2.82)\end{array}$ & $\begin{array}{l}< \\
0.001\end{array}$ & $\begin{array}{l}-0.21(-1.99 \\
1.57)\end{array}$ & 0.817 \\
\hline \multicolumn{11}{|c|}{ + Physical Activity } \\
\hline Yes MetS & $\begin{array}{l}-3.18(-5.27 ;- \\
1.08)\end{array}$ & 0.003 & $\begin{array}{l}-2.40(-3.73 ;- \\
1.08)\end{array}$ & $\begin{array}{l}< \\
0.001\end{array}$ & $\begin{array}{l}-2.92(-6.23 \\
0.39)\end{array}$ & 0.084 & $\begin{array}{l}-2.50(-4.12 ;- \\
0.88)\end{array}$ & 0.003 & $\begin{array}{l}0.00(-1.76 \\
1.76)\end{array}$ & 1.000 \\
\hline $\begin{array}{l}\text { Physical } \\
\text { Activity } \\
\text { (Sufficiently } \\
\text { active) }\end{array}$ & $4.11(1.69 ; 6.53)$ & 0.001 & $4.03(2.60 ; 5.45)$ & $\begin{array}{l}< \\
0.001\end{array}$ & 5.70 (2.88: 8.52) & $\begin{array}{l}< \\
0.001\end{array}$ & $7.50(5.32 ; 9.68)$ & $\begin{array}{l}< \\
0.001\end{array}$ & $4.00(1.44 ; 6.56)$ & 0.002 \\
\hline
\end{tabular}

$\mathrm{Cl}=$ Confidence interval

Differences in median levels were analysed with quantile regression models; a negative effect indicates a lower median score

Adjusted for sex, age, education level and study area

Categorized according to WHO Physical Activity Guidelines

Inactive: $<150$ min of MPA and $<75$ VPA per week

Sufficiently active: $>150$ min of MPA or $>75$ VPA per week.

Metabolic syndrome: Any three of the following values: Blood glucose $\geq 5.6 \mathrm{mmol} / \mathrm{L}$ (Hba1C $\geq 5.7 \%$ in SAPALDIA4); waist circumference $\geq 94 \mathrm{~cm}$ in men \& $\geq 80 \mathrm{~cm}$ in women; systolic blood pressure $\geq 130$ or diastolic blood pressure $\geq 85$; hdl $<1.0 \mathrm{mmol} / \mathrm{L}$ in men $\&<1.3 \mathrm{mmol} / \mathrm{L}$ in women; triglycerides $\geq 1.7 \mathrm{mmol} / \mathrm{L}$ 
compared to the reference class. The association results of the latent classes with HRQoL did not substantially differ when adjusting for physical activity in the model, although they tended to become somewhat weaker. We observed statistically significant positive associations for being physically active (i.e. meeting WHO guidelines) with all HRQoL domains. Coefficients ranged from 3.92 to 7.50 for the comparison of meeting vs. not meeting WHO physical activity guidelines. The median scores and descriptive differences of the latent classes (without adjustment of physical activity) can be found in Additional Fig. 1.

Participants with MetS showed associations in the same direction with HRQoL domains as the Unhealthy group (Table 4B). Neither MetS nor the class "Unhealthy" were associated with the MH domain. The associations did not differ substantially after adjustment for physical activity. As in the model with the latent classes, physically active subjects had higher HRQoL scores in all domains.

\section{Cross-sectional HRQoL associations of composite variables combining physical activity with latent classes and MetS, respectively (SAPALDIA4)}

Figure 2 shows the results of the quantile regression models of for the composite variables cross-categorizing participants based on their physical activity and their latent class or MetS, respectively, and their association with HRQoL domains. We observed (Fig. 2A) that compared to the reference group (Healthy \& active) all categories had coefficients in the direction of lower HRQoL scores, irrespective of the domain considered. Moreover, within latent class categories the inactive groups consistently exhibited lower scores on average than the active one. The lowest HRQoL scores were observed in the unhealthy and physically inactive group compared to the healthy and physically active group for the GH, PF, and BP domain. This group even exhibited statistically significantly lower scores in the $\mathrm{MH}$ domain compared to the same reference group.

The association patterns for the composite MetS/physical activity variables with HRQoL (Fig. 2B) were

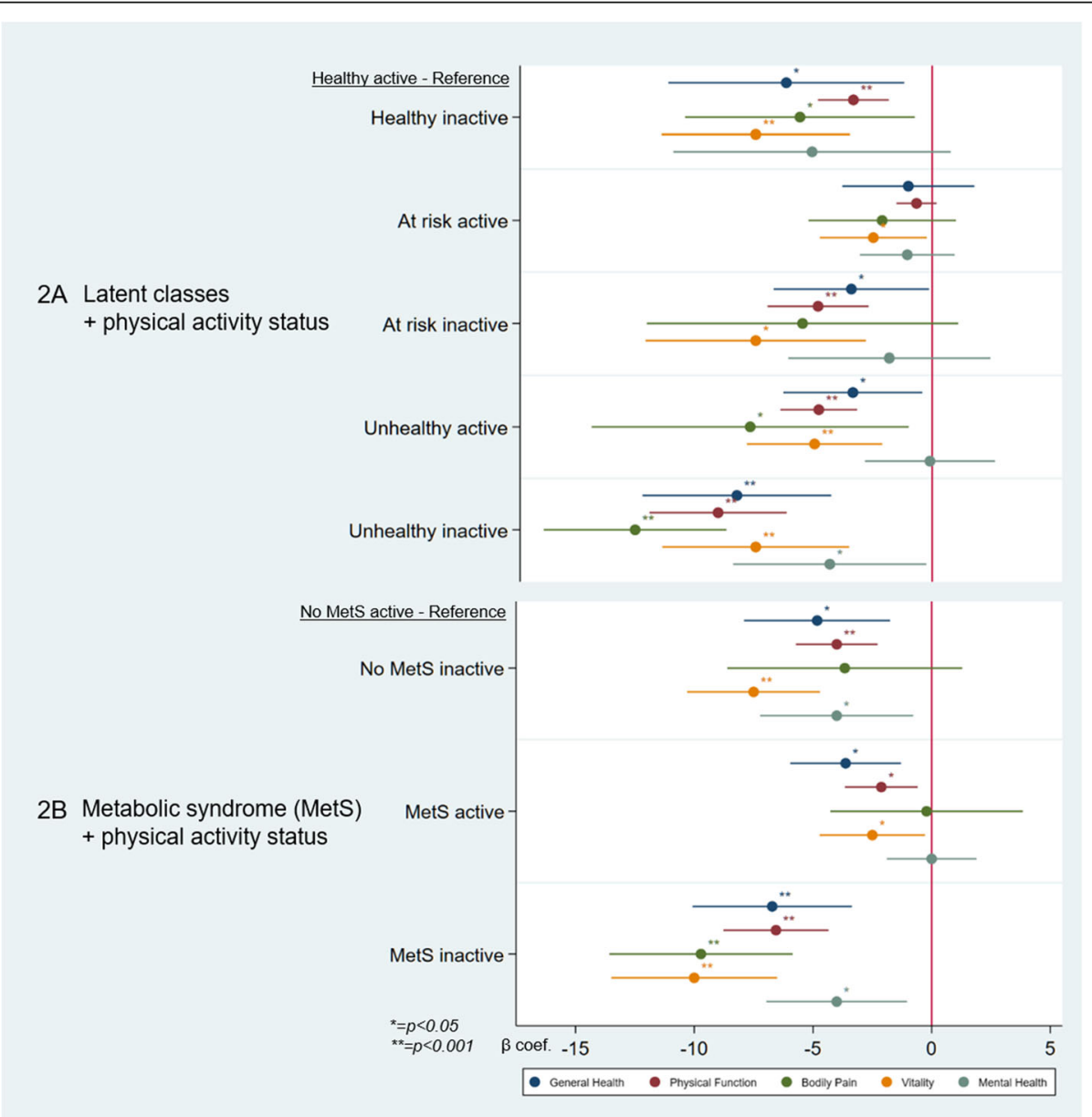

Fig. 2 Cross-sectional adjusted HRQoL associations of categories combining physical activity with latent classes (2A) as well as metabolic syndrome (2B) (SAPALDIA4) 
consistent with the association patterns for the composite variable considering latent classes instead of MetS.

The exact coefficients for Fig. 2A and B can be seen in Additional Table 7.

\section{Prospective associations of composite variables} combining physical activity with latent classes and MetS, respectively, at SAPALDIA3 with HRQoL at SAPALDIA4

The longitudinal results are displayed in Table 5 . We observed statistically significant differences compared to the Healthy \& active group of -4.95 (95\% CI: - 7.01; 2.90) points in effect score for the association of the Unhealthy \& inactive group with GH. Furthermore, the Unhealthy \& active group scored $-2.47(-4.32 ;-0.81)$ points in effect score less in the PF domain compared to the reference group. The At risk \& inactive group showed statistically significantly lower scores for the VT domain of $-2.29(-4.34 ;-0.23)$ points in effect scores. Similar to Table 4 we detected generally lower HRQoL scores in inactive participants in the Unhealthy group, but the same pattern was not as consistently observed in the Healthy and At risk groups.
In Table 5B we detected no differences in HRQoL scores by physical activity status among the participants without MetS. In contrast, among persons with MetS, HRQoL scores were consistently lower for inactive participants. The difference reached statistical significance for $\mathrm{GH}$, and PF. In the MetS group the sufficiently active and inactive, respectively, had $-0.43(95 \% \mathrm{CI}:-2.38$; $1.53)$ and $-4.83(-7.89 ;-1.78)$ lower scores for $\mathrm{GH}$ as well as $-1.79(-2.80 ;-0.79)$ and $-2.48(-4.46 ;-0.50)$ lower scores for PF, when compared to active subjects without MetS. The Mets \& active group showed statistically significant differences, compared to the reference group (NoMetS \& active) in the MH domain of 1.92 (0.31: 3.53).

\section{Associations of composite variables combining physical activity with latent classes and MetS, respectively, with health service utilization (SAPALDIA4)}

Table 6A displays the association of composite variables with self-reported health service use in the year before SAPALDIA4. While no associations were observed with physician's visits, participants in the Unhealthy \& inactive group (OR 2.69 (1.52; 4.74)) and At risk \& inactive

Table 5 Prospective associations of composite variable categories defined by latent classes (Table A9A) and metabolic syndrome (Table A9B), respectively, and physical activity status at SAPALDIA3, with median levels of HRQoL at SAPALDIA4, adjusted for respective HRQOL domain at SAPALDIA3

\begin{tabular}{|c|c|c|c|c|c|c|c|c|c|c|}
\hline \multirow[t]{2}{*}{$N=902$} & \multicolumn{2}{|c|}{ General Health (GH) } & \multicolumn{2}{|c|}{ Physical Functioning (PF) } & \multicolumn{2}{|l|}{ Bodily Pain (BP) } & \multicolumn{2}{|l|}{ Vitality (VT) } & \multicolumn{2}{|l|}{ Mental Health (MH) } \\
\hline & $\begin{array}{l}\text { Coefficient } \\
(95 \% \mathrm{Cl})\end{array}$ & $\begin{array}{l}P \text { - } \\
\text { value }\end{array}$ & $\begin{array}{l}\text { Coefficient }(95 \% \\
\mathrm{CI})\end{array}$ & $\begin{array}{l}P \text { - } \\
\text { value }\end{array}$ & $\begin{array}{l}\text { Coefficient }(95 \% \\
\text { Cl) }\end{array}$ & $\begin{array}{l}P \text { - } \\
\text { value }\end{array}$ & $\begin{array}{l}\text { Coefficient }(95 \% \\
\mathrm{CI})\end{array}$ & $\begin{array}{l}P \text { - } \\
\text { value }\end{array}$ & $\begin{array}{l}\text { Coefficient }(95 \% \\
\text { Cl) }\end{array}$ & $\begin{array}{l}P \text { - } \\
\text { value }\end{array}$ \\
\hline \multicolumn{11}{|l|}{$\begin{array}{l}\text { 5A. Latent classes } \\
+ \text { Physical Activity }\end{array}$} \\
\hline Healthy \& active & Reference & & & & & & & & & \\
\hline Healthy \& inactive & $-0.36(-2.56 ; 2.84)$ & 0.749 & $-0.24(-1.69 ; 1.21)$ & 0.741 & $0.00(-4.69 ; 4.69)$ & 1.000 & $-0.32(-3.64 ; 3.00)$ & 0.849 & $0.57(-3.69 ; 4.83)$ & 0.792 \\
\hline At risk \& active & $\begin{array}{l}-2.02(-4.50 \\
0.40)\end{array}$ & 0.100 & $-0.69(-1.81 ; 0.42)$ & 0.223 & $0.00(-1.72 ; 1.72)$ & 1.000 & $-1.00(-3.11 ; 1.13)$ & 0.359 & $-0.57(-2.20 ; 1.06)$ & 0.492 \\
\hline At risk \& inactive & $\begin{array}{l}-0.92(-4.05 \\
2.21)\end{array}$ & 0.564 & $\begin{array}{l}-1.03(-2.52 ;- \\
0.46)\end{array}$ & 0.175 & $-0.62(-4.95 ; 3.71)$ & 0.778 & $-1.29(-4.93 ; 2.34)$ & 0.485 & $\begin{array}{l}-2.29(-4.34 ;- \\
0.23)\end{array}$ & 0.029 \\
\hline $\begin{array}{l}\text { Unhealthy \& } \\
\text { active }\end{array}$ & $\begin{array}{l}-1.63(-4.03 \\
0.76)\end{array}$ & 0.181 & $\begin{array}{l}-2.57(-4.32 ;- \\
0.81)\end{array}$ & 0.004 & $-0.69(-4.71 ; 3.33)$ & 0.737 & $-0.13(-2.70 ; 2.45)$ & 0.922 & $0.00(-2.64 ; 2.64)$ & 1.000 \\
\hline $\begin{array}{l}\text { Unhealthy \& } \\
\text { inactive }\end{array}$ & $\begin{array}{l}-4.95(-7.01 ;- \\
2.90)\end{array}$ & $\begin{array}{l}< \\
0.001\end{array}$ & $-3.55(-8.41 ; 1.31)$ & 0.152 & $\begin{array}{l}-5.42(-15.45 \\
4.61)\end{array}$ & 0.289 & $0.04(-3.71 ; 3.80)$ & 0.981 & $1.71(-3.88 ; 7.31)$ & 0.547 \\
\hline \multicolumn{11}{|c|}{$\begin{array}{l}\text { 5B. Metabolic Syndrome } \\
\text { + Physical Activity }\end{array}$} \\
\hline No MetS \& active & Reference & & & & & & & & & \\
\hline $\begin{array}{l}\text { No MetS \& } \\
\text { inactive }\end{array}$ & $1.03(-1.28 ; 3.34)$ & 0.381 & $0.32(-0.79 ; 1.44)$ & 0.569 & $0.00(-4.67 ; 4.67)$ & 1.000 & $1.64(-0.83 ; 4.11)$ & 0.192 & $0.55(-2.08 ; 3.18)$ & 0.663 \\
\hline MetS \& active & $-0.43(-2.38 ; 1.53)$ & 0.668 & $\begin{array}{l}-1.79(-2.80 ;- \\
0.79)\end{array}$ & $\begin{array}{l}< \\
0.001\end{array}$ & $0.00(-1.27 ; 1.27)$ & 1.000 & $1.74(-0.16 ; 3.64)$ & 0.072 & $1.92(0.31: 3.53)$ & 0.020 \\
\hline MetS \& inactive & $\begin{array}{l}-4.83(-7.89 ;- \\
1.78)\end{array}$ & 0.002 & $\begin{array}{l}-2.48(-4.46 ;- \\
0.50)\end{array}$ & 0.014 & $-1.38(-5.42 ; 2.66)$ & 0.504 & $-2.19(-5.80 ; 1.43)$ & 0.235 & $0.51(-2.97 ; 3.98)$ & 0.776 \\
\hline
\end{tabular}

$\mathrm{Cl}=$ Confidence interval

Differences in median levels were analysed with quantile regression models; a negative effect indicates a lower median score

Adjusted for sex, age, education level, study area, and HRQoL at SAPALDIA3

Categorized according to WHO Physical Activity Guidelines

Inactive: $<150 \mathrm{~min}$ of MPA and $<75$ VPA per week

Sufficiently active: $>150$ min of MPA or $>75$ VPA per week

Metabolic syndrome: Any three of the following values: Blood glucose $\geq 5.6 \mathrm{mmol} / \mathrm{L}$ ( $\mathrm{Hba} 1 \mathrm{C} \geq 5.7 \%$ in SAPALDIA4); waist circumference $\geq 94 \mathrm{~cm}$ in men \& $\geq 80 \mathrm{~cm}$ in women; systolic blood pressure $\geq 130$ or diastolic blood pressure $\geq 85 ;$ hdl $<1.0 \mathrm{mmol} / \mathrm{L}$ in $\mathrm{men} \&<1.3 \mathrm{mmol} / \mathrm{L}$ in women; triglycerides $\geq 1.7 \mathrm{mmol} / \mathrm{L}$ 
(2.09 $(1.14 ; 3.81))$ group exhibited the highest risk for a hospitalization in the previous 12 months compared to participants in the reference group (Healthy \& active).

The risk of hospitalization was also strongest for the group MetS \& inactive $(2.63(1.64 ; 4.22))$ and No MetS \& inactive group $(2.26(1.38 ; 3.72))$, compared to the reference group (Table 6B). Same as for the latent classes, the associations with physician's visit did not show a pattern of a higher likelihood among inactive persons without MetS.

\section{Sensitivity analyses}

In the sub-sample of subjects not reporting any cardiovascular diseases we found cross-sectional and longitudinal associations with HRQoL and cross-sectional associations with health service utilization comparable to those in the overall sample for both, composite variables based on latent classes and on MetS, respectively (Additional Table 8 and 9 for HRQoL; Additional Table 10 for health service utilization).

\section{Discussion}

In this general population sample from Switzerland, HRQoL derived from SF-36 was generally high compared to similar settings and age groups [38].

The use of LCA enabled us to cluster physiological functioning of the SAPALDIA general population sample and identify three latent classes that were comparable over two time points almost 10 years apart (SAPALDIA3\&4). This longer-term clustering of physiological functioning is likely the result of temporal tracking of lifestyle and behavioral habits. The class termed "Unhealthy" characterized with a high percentage of participants with obesity and a high percentage of body fat in the presence of cardio-metabolic pathophysiology was associated with considerably lower HRQoL scores in all physical component scores of HRQoL. The largest difference to the "Healthy" reference class in terms of median scores was found for the PF and BP domains, which were also lower in the "At risk" class. Differences in HRQoL between classes were larger for physical compared to mental health components. Yet, the VT subdomain, belonging to the mental health component also showed considerable differences for the Unhealthy class compared to the Healthy class. Even though the coefficients were smaller and in part statistically not significant in the longitudinal analysis, we found similar results as in the cross-sectional analyses. These consistent results give an indication on prospective pathways leading from the latent classes to decreased HRQoL. As we adjusted for HRQoL at baseline (SAPALDIA3), we may also argue that reverse causality has been partly excluded, even though much more evidence is needed to prove this hypothesis. Of interest from a primary prevention perspective is the fact that the observed crosssectional and longitudinal associations were not driven

Table 6 Cross-sectional associations of composite variable categories defined by latent classes (Table A10A) and metabolic syndrome (Table A10B), respectively, and physical activity status with health service utilization in the last 12 months (SAPALDIA4)

\begin{tabular}{|c|c|c|c|c|c|c|}
\hline \multirow{2}{*}{$\begin{array}{l}N=1124 \\
6 \text { A. Latent classes } \\
+ \text { Physical Activity }\end{array}$} & \multicolumn{2}{|l|}{ Physician visit } & \multicolumn{2}{|l|}{ Hospital visit } & \multirow{2}{*}{$\begin{array}{l}\text { Combined } \\
\text { Odds ratio }(95 \% \mathrm{Cl})\end{array}$} & \multirow[b]{2}{*}{ P-value } \\
\hline & $\begin{array}{l}\text { Odds ratio } \\
(95 \% \mathrm{Cl})\end{array}$ & $\overline{P \text {-value }}$ & Odds ratio $(95 \% \mathrm{Cl})$ & $\overline{P \text {-value }}$ & & \\
\hline Healthy \& active & Reference & & & & & \\
\hline Healthy \& inactive & $1.22(0.59 ; 2.53)$ & 0.596 & $1.79(0.89 ; 3.59)$ & 0.101 & $1.15(0.55 ; 2.40)$ & 0.702 \\
\hline At risk \& active & $1.02(0.65 ; 1.60)$ & 0.927 & $0.97(0.57 ; 1.64)$ & 0.910 & $0.99(0.63 ; 1.57)$ & 0.980 \\
\hline At risk \& inactive & $1.11(0.61 ; 2.03)$ & 0.722 & $2.09(1.14 ; 3.81)$ & 0.017 & $1.05(0.58 ; 1.92)$ & 0.868 \\
\hline Unhealthy \& active & $1.68(0.96 ; 2.95)$ & 0.069 & $1.44(0.81 ; 2.53)$ & 0.211 & $1.64(0.93 ; 2.91)$ & 0.089 \\
\hline Unhealthy \& inactive & $1.03(0.58 ; 1.85)$ & 0.908 & $2.69(1.52 ; 4.74)$ & 0.001 & $1.13(0.62 ; 2.06)$ & 0.701 \\
\hline
\end{tabular}

6B. Metabolic syndrome (MetS)

+ Physical activity

No MetS \& active Reference

No MetS \& inactive

$0.90(0.55 ; 1.47)$

0.673

$2.26(1.38 ; 3.72)$

0.001

$0.85(0.52 ; 1.39)$

0.527

MetS \& active

$1.64(1.07 ; 2.54)$

$1.52(0.98 ; 2.38)$

0.060

$1.54(0.99 ; 2.38)$

0.053

MetS \& inactive

$1.49(0.90 ; 2.45)$

0.120

$2.63(1.64 ; 4.22)$

$<0.001$

$1.57(0.93 ; 2.66)$

0.093

$\mathrm{Cl}=$ Confidence interval

Probabilities were calculated using logistic regression models for binary outcomes

Outcomes: 0 vs. $\geq 1$

Adjustued Variables: Sex, age, education level and study area

Physical Activity Guidelines (WHO)

Inactive: $<150$ min of MPA and $<75$ VPA per week

Sufficiently active: $>150 \mathrm{~min}$ of MPA or $>75$ VPA per week.

Metabolic syndrome: Any three of the following values: Blood glucose $\geq 5.6 \mathrm{mmol} / \mathrm{L}$ (Hba1C $\geq 5.7 \%$ in SAPALDIA4); waist circumference $\geq 94 \mathrm{~cm}$ in men \& $\geq 80 \mathrm{~cm}$ in women; systolic blood pressure $\geq 130$ or diastolic blood pressure $\geq 85 ; \mathrm{hdl}<1.0 \mathrm{mmol} / \mathrm{L}$ in men $\&<1.3 \mathrm{mmol} / \mathrm{L}$ in women; triglycerides $\geq 1.7 \mathrm{mmol} / \mathrm{L}$ 
by the sub-group of persons who had already progressed to a clinical diagnosis of cardiovascular disease. Our results thus underline the relevance and also opportunity to improve HRQoL at older age through interventions that promote a healthy lifestyle in the "middle-aged" group.

The risk factors being more prevalent in members of the "Unhealthy Class" agreed well with the cluster of risk factors defining the MetS [13]. Although there is not yet much, and mostly cross-sectional evidence on an association of MetS with HRQoL, most studies showed a worsening effect of the MetS on HRQoL, which we support with our findings. However, it was also observed that the MetS alone without accompanying comorbidities such as depression had little or no effect on HRQoL [39-41]. In our study, we observed that the MetS was associated with lower HRQoL and also a higher rate of hospitalization in the 12 month period before the assessment, even in the absence of cardiovascular disease. Our results are in line with recent intervention studies demonstrating that lifestyle changes can improve HRQoL among persons with MetS [14, 42]. Additional longitudinal research is needed to elaborate more on possible causal pathways.

In this study, we were specifically interested in assessing whether the promotion of physical activity in aging populations can attenuate the short- and longer-term adverse consequences of poor physiological functioning and of the MetS on HRQoL. As previously reported, physical activity levels were high in this population (73\% of participants meeting WHO guidelines [43]), but aligned with the results of the Swiss Health Survey, which reported $76 \%$ of adults being sufficiently active in Switzerland [44]. Consistent with the literature, we observed strong and independent positive associations of physical activity with HRQoL [17, 21, 45, 46].

We observed in a remarkably consistent way that physical inactivity was associated with lower HRQoL scores in many domains, both in all latent classes and in persons with and without MetS. For the physical functioning domains, HRQoL scores were mostly lowest in physically inactive persons assigned to the Unhealthy class as well as combined with the presence of the MetS. These results are in line with the few randomized controlled trials demonstrating the benefit of physical activity for HRQoL in subjects with MetS or cardiovascular diseases [47-50].

The direct associations of physical activity with HRQoL and the moderating influence of physical activity on the association of the "Unhealthy" latent class as well as of MetS with HRQoL underline the pivotal role of physical activity in preventing and mitigating diseases [51]. Physical activity is of crucial importance, not only from a medical perspective, but also from a health- economic perspective, as it represents the most costeffective approach in the prevention and rehabilitation of cardio-metabolic and aging-induced comorbidities $[42,51,52]$. In this study we found in fact the highest risk for a recent hospitalization in persons exhibiting both, MetS or "Unhealthy" latent class as well as physical inactivity, even in the absence of a cardiovascular diagnosis.

Results from previous research on the association of single components making up the "Unhealthy" class with HRQoL domains are mostly consistent with our findings $[11,12]$. Even after controlling for other important health-risk behaviors, an increased BMI seems to be most strongly associated with adverse HRQoL outcomes $[6,17]$. A recent systematic review supports these findings and stated that obesity is associated with lower HRQoL outcomes [53]. Another systematic review showed that being overweight or obese resulted in fewer points in the main domains of HRQoL [4], in line with our results. Next to this, hyperglycemia was shown to have direct and indirect effects through inadequate glycemic control on HRQoL outcomes in diabetic elderly [54]. Intervention plans to promote lifestyle changes prevented frailty in diabetic individuals and enhanced life expectancy and HRQoL [55].

In this study, we observed a clear socio-economic gradient across the three latent classes, with participants at the lowest educational level being over-represented in the class with the lowest HRQoL scores. Socio-economic gradients have previously been identified for obesity and associated lifestyles [56-62], for the MetS [63-65], and for HRQoL $[66,67]$. Factors that are likely to contribute to these social gradients include the understanding of healthy habits, access to healthy habits (e.g. access to fitness centers; prices for healthy vs. unhealthy food; green spaces and built environment) and access to health services (i.e. regular testing of blood pressure, glycemia, lipids) as well as access to adequate control of disease (i.e. blood pressure medication) [56-58].

\section{Strength and limitations}

The information on socio-economic status and physical activity were self-reported by the participants, which could lead to measurement errors. The fact that participants at SAPALDIA3 were interviewed, whereas at SAPALDIA4 participants self-administered questionnaires, could have introduced differential misclassification of physical activity. But it is unlikely that this would have altered the main messages of our study, given the consistency of longitudinal and cross-sectional results. All other variables included in the analysis were objectively assessed. Triglyceride and glycemia tests and the type of blood as test source (venous versus capillary blood) differed between SAPALDIA3 and SAPALDIA4. 
While this could again be the source of differential misclassification over time, the consistency of the crosssectional and longitudinal results suggests this bias to be minimal. The variables reflecting cardio-metabolic physiological functioning were chosen based on the evidence reported in the literature. Our current LCA may furthermore be sensitive to the chosen categories for the predictor variables. Yet, the consistency in results between latent classes and MetS points to the fact that the chosen cutoffs for categorization are clinically relevant. As in any cohort, we cannot exclude bias due to loss-tofollow-up. Several of the factors leading to or included in the categorization of participant's physiological functioning influenced participation at follow-up. Persons with healthy habits were more likely to participate in SAPALDIA4. Older persons were less likely to participate at follow-up, in part because they had died. It is therefore likely that the effect of poor health habits including obesity and physiological functioning on HRQoL was underestimated. Given this loss-to-follow-up, the SAPALDIA4 participants are most likely no longer representative of the current general population in Switzerland. Yet, with regard to physical activity the observed distribution in our study sample is highly comparable to the distribution recently observed in the population-based Swiss Health Survey. The generalizability of our findings to other study settings needs testing, particularly in the light of the very high physical activity level of the Swiss population in general [43].

Despite these limitations, the findings of this study strongly support that it is possible to reduce the number of physiological functioning variables using LCA. The latent classes corresponded well with the cluster of the MetS, which underlines the significant interplay of these variables.

The LCA was facilitated by access to data from the SAPALDIA participants, who are deeply characterized on various physiological domains. The population-based design of the study is an important prerequisite for the generalizability of the findings, at least within the Swiss setting, although participation and survivor bias always pose a threat to validity and generalizability of any longrunning cohort. Finally, the longitudinal design of this study adds knowledge to possible pathways in the investigated associations.

\section{Conclusion}

This study, investigating associations of HRQoL with cardio-metabolic physiological functioning parameters combined with physical activity status in a general population sample, emphasizes the relevance of promoting primary and secondary prevention to maintain wellbeing in aging populations. In a country like Switzerland with sufficient economic resources, the lack of investments into primary and secondary prevention [68] seems to come at the cost of poor well-being in persons in the second half of their life. This may lead to high treatment costs later in life and to loss of productivity in persons still actively engaged in the workforce [69, 70].

Furthermore, the underrepresentation of primary prevention and screening programs in disease control leads to the clustering of factors among the lower social classes and therefore to inequality in HRQoL despite the strong economy of Switzerland. In the light of increased promotion of personalized medicine as opposed to public health and prevention programs, as well as imbalanced investments into medical treatments, our results may help to understand and guide how to avoid further widening of medical inequalities. This study primarily underlines the importance of physical activity promotion on health and quality of life outcomes of the factors making up the metabolic syndrome.

\section{Supplementary information}

Supplementary information accompanies this paper at https://doi.org/10. 1186/s12955-020-01557-Z.

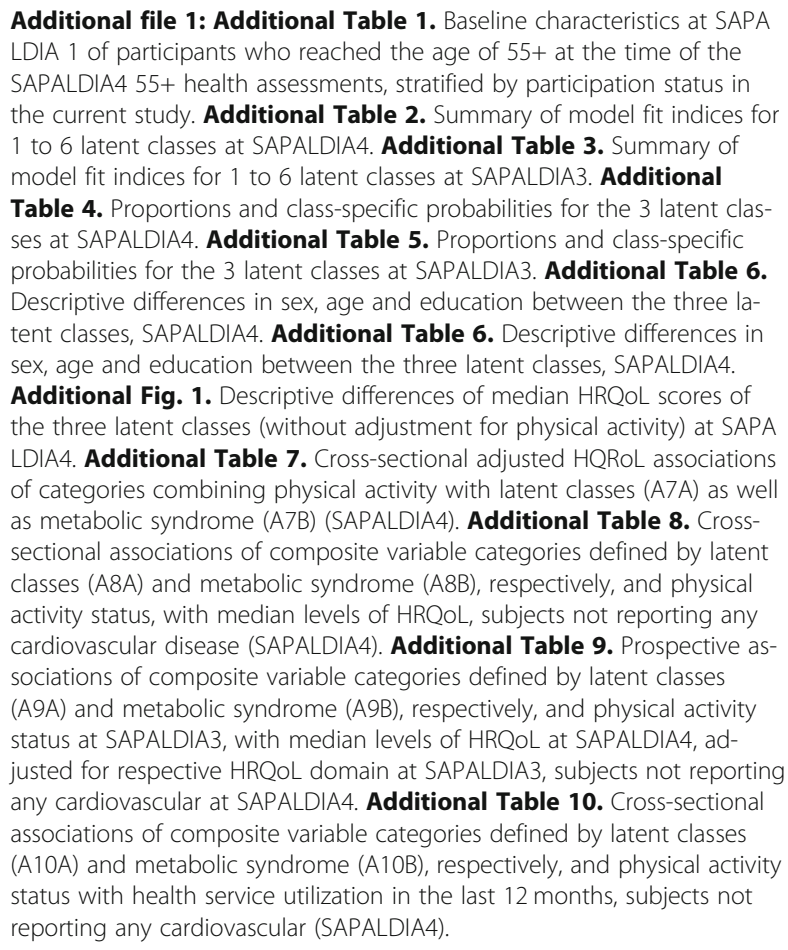

\section{Abbreviations}

HRQoL: Health-related quality of life; LCA: Latent class analysis;

MetS: Metabolic syndrome; BMI: Body mass index; SF-36: Short-Form Health Survey; QoL: Quality of life; SAPALDIA: Swiss Study on Air Pollution and Lung and Heart Diseases; PF: Physical functioning; BP: Bodily pain; RP: Rolephysical; GH: General health; VT: Vitality; SF: Social role functioning; RE: role emotional; $\mathrm{MH}$ : Mental health; BIA: Bio-impedance analysis; BIC: Bayesian 
information criterion; AIC: Akaike Information Criterion; Cl: Confidence interval

\section{Acknowledgements}

The study could not have been done without the help of the study participants, technical and administrative support and the medical teams and field workers at the local study sites.

\section{Authors' contributions}

$\mathrm{NPH}$ and PC substantially contributed to design, analysis and interpretation of the data as well as drafting and revising the manuscript. DK and CS have made major contribution to statistical analysis and review of the manuscript. Ml contributed in writing parts of the manuscript and by thoroughly reviewing and editing. All authors read and approved the final manuscript.

\section{Funding}

This word was supported by the Swiss National Science Foundation (grants no 33CS30-177506/1).

\section{Availability of data and materials}

Not applicable.

\section{Ethics approval and consent to participate}

The SAPALDIA cohort study complied with the Declaration of Helsinki. For each survey, ethics approval was granted by the regional ethics committees and participants provided written informed consent prior to participation.

\section{Consent for publication}

Not applicable.

\section{Competing interests}

The authors declare that they have no conflict of interest.

Received: 24 September 2019 Accepted: 9 September 2020

\section{Published online: 20 October 2020}

\section{References}

1. Desa UJWP. World population prospects: The 2015 revision, key findings and advance tables. 2015.

2. Gao T, Wang XC, Chen R, Ngo HH, Guo W. Disability adjusted life year (DALY): a useful tool for quantitative assessment of environmental pollution. Sci Total Environ. 2015;511:268-87.

3. Vos T, Barber RM, Bell B, Bertozzi-Villa A, Biryukov S, Bolliger I, et al. Global, regional, and national incidence, prevalence, and years lived with disability for 301 acute and chronic diseases and injuries in 188 countries, 1990-2013: a systematic analysis for the Global Burden of Disease Study 2013. Lancet. 2015:386(9995):743-800

4. Corica F, Bianchi G, Corsonello A, Mazzella N, Lattanzio F, Marchesini GJP. Obesity in the context of aging: quality of life considerations. Pharmacoeconomics. 2015;33(7):655-72.

5. Leadley RM, Armstrong N, Reid KJ, Allen A, Misso KV, Kleijnen JJPP. Healthy aging in relation to chronic pain and quality of life in Europe. 2014;14(6): 547-58.

6. Dey M, Gmel G, Mohler-Kuo MJB. Body mass index and health-related quality of life among young Swiss men. 2013;13(1):1028.

7. Priano SM, Hong OS, Chen J-LJN. Lifestyles and health-related outcomes of US hospital nurses: A systematic review. 2018;66(1):66-76.

8. Ford ES, Zhao G, Tsai J, Li CJA. Low-risk lifestyle behaviors and all-cause mortality: findings from the National Health and Nutrition Examination Survey III Mortality Study. 2011;101(10):1922-9.

9. McGregor RA, Cameron-Smith D, Poppitt SDJ, healthspan. It is not just muscle mass: a review of muscle quality, composition and metabolism during ageing as determinants of muscle function and mobility in later life. 2014;3(1):9.

10. Laska MN, Pasch KE, Lust $\mathrm{K}$, Story M, Ehlinger EJPS. Latent class analysis of lifestyle characteristics and health risk behaviors among college youth. 2009; 10(4):376-86.

11. Gouveia ÉRQ, Gouveia BR, Ihle A, Kliegel M, Maia JA, i Badia SB, et al. Correlates of health-related quality of life in young-old and old-old community-dwelling older adults. 2017;26(6):1561-9.
12. Knox E, Muros JJJE. Association of lifestyle behaviours with self-esteem through health-related quality of life in Spanish adolescents. 2017;176(5): 621-8.

13. Carriere I, Pérès $K$, Ancelin ML, Gourlet V, Berr C, Barberger-Gateau P, et al. Metabolic syndrome and disability: findings from the prospective three-city study. 2013;69(1):79-86

14. Saboya PP, Bodanese LC, Zimmermann PR, Gustavo AD, Assumpção CM, Londero F. Metabolic syndrome and quality of life: a systematic review. Rev Lat Am Enfermagem. 2016;24:e2848.

15. Beavers KM, Miller ME, Rejeski WJ, Nicklas BJ, Kritchevsky SBJJGSABS, Sciences M. Fat mass loss predicts gain in physical function with intentional weight loss in older adults. 2012;68(1):80-6.

16. Batsis JA, Germain CM, Vásquez E, Zbehlik AJ, Bartels SJJJPA, Health. Physical activity predicts higher physical function in older adults: the osteoarthritis initiative. 2016:13(1):6-16

17. Marcos-Delgado A, Fernández-Villa T, Martínez-González M, Salas-Salvadó J, Corella D, Castañer O, et al. The Effect of Physical Activity and High Body Mass Index on Health-Related Quality of Life in Individuals with Metabolic Syndrome. Int J Environ Res Public Health. 2020;17(10).

18. Foster HME, Celis-Morales CA, Nicholl BI, Petermann-Rocha F, Pell JP, Gill $J M R$, et al. The effect of socioeconomic deprivation on the association between an extended measurement of unhealthy lifestyle factors and health outcomes: a prospective analysis of the UK Biobank cohort. Lancet Public Health. 2018;3(12):e576-e85.

19. Lv J, Yu C, Guo Y, Bian Z, Yang L, Chen Y, et al. Adherence to Healthy Lifestyle and Cardiovascular Diseases in the Chinese Population. J Am Coll Cardiol. 2017;69(9):1116-25.

20. Setters B. Holmes HMJPCCiOP. Hypertens Older Adult. 2017;44(3):529-39

21. Abdelbasset WK, Alsubaie SF, Tantawy SA, Elyazed TIA, Elshehawy AAJM. A cross-sectional study on the correlation between physical activity levels and health-related quality of life in community-dwelling middle-aged and older adults. 2019:98(11).

22. Ackermann-Liebrich U, Kuna-Dibbert B, Probst-Hensch NM, Schindler C, Dietrich DF, Stutz EZ, et al. Follow-up of the Swiss Cohort Study on Air Pollution and Lung Diseases in Adults (SAPALDIA 2) 1991-2003: methods and characterization of participants. 2005:50(4):245-63.

23. Endes S, Schaffner E, Caviezel S, Dratva J, Stolz D, Schindler C, et al. Is physical activity a modifier of the association between air pollution and arterial stiffness in older adults: the SAPALDIA cohort study. 2017;220(6): 1030-8.

24. Sheikh MA, Abelsen B, Olsen JA. Education and health and well-being: direct and indirect effects with multiple mediators and interactions with multiple imputed data in Stata. J Epidemiol Community Health. 2017;71(11): 1037-45.

25. Hart PD, Kang M, Weatherby NL, Lee YS, Brinthaupt TMJWJPM. Systematic review of health-related quality of life assessments in physical activity research. 2015:3(2):28-39.

26. Keller SD, Ware JE Jr, Bentler PM, Aaronson NK, Alonso J, Apolone G, et al. Use of structural equation modeling to test the construct validity of the SF36 health survey in ten countries: Results from the IQOLA project. 1998; 51(11):1179-88.

27. Keller SD, Ware JE Jr, Bentler PM, Aaronson NK, Alonso J, Apolone G, et al. Use of structural equation modeling to test the construct validity of the SF36 Health Survey in ten countries: results from the IQOLA Project. International Quality of Life Assessment. J Clin Epidemiol. 1998:51(11):1179_ 88.

28. Jenkinson C, Wright L, Coulter A. Criterion validity and reliability of the SF36 in a population sample. Qual Life Res. 1994;3(1):7-12.

29. Framework ICJMC. The MOS 36-item short-form health survey (SF-36). 1992; 30(6):473-83.

30. Endes S, Caviezel S, Schaffner E, Dratva J, Schindler C, Künzli N, et al. Associations of Novel and Traditional Vascular Biomarkers of Arterial Stiffness: Results of the SAPALDIA 3 Cohort Study. PLoS One. 2016;11(9): e0163844

31. Dratva J, Caviezel S, Schaffner E, Bettschart R, Kuenzli N, Schindler C, et al. Infectious diseases are associated with carotid intima media thickness in adolescence. Atherosclerosis. 2015;243(2):609-15

32. Reboussin DM, Allen NB, Griswold ME, Guallar E, Hong Y, Lackland DT, et al. Systematic review for the 2017 ACC/AHA/AAPA/ABC/ACPM/AGS/APhA/ ASH/ASPC/NMA/PCNA guideline for the prevention, detection, evaluation, and management of high blood pressure in adults: a report of the 
American College of Cardiology/American Heart Association Task Force on Clinical Practice Guidelines. 2018;71(19):2176-98.

33. Nishida C, Mucavele PJS. Monitoring the rapidly emerging public health problem of overweight and obesity: the WHO Global Database on Body Mass Index. 2005;29:5-11.

34. Cohen RM, Haggerty S, Herman WH. HbA1c for the diagnosis of diabetes and prediabetes: is it time for a mid-course correction? Oxford University Press; 2010.

35. Jessani S, Watson T, Cappuccio F, Lip GJJ. Prevention of cardiovascular disease in clinical practice: The Joint British Societies'(JBS 2) guidelines. 2006; 20(9):641.

36. Alberti KG, Eckel RH, Grundy SM, Zimmet PZ, Cleeman Jl, Donato KA, et al. Harmonizing the metabolic syndrome: a joint interim statement of the International Diabetes Federation Task Force on Epidemiology and Prevention; National Heart, Lung, and Blood Institute; American Heart Association; World Heart Federation; International Atherosclerosis Society; and International Association for the Study of Obesity. Circulation. 2009; 120(16):1640-5.

37. Yang C-CJCS, Analysis D. Evaluating latent class analysis models in qualitative phenotype identification. 2006;50(4):1090-104.

38. Hopman WM, Towheed T, Anastassiades T, Tenenhouse A, Poliquin S, Berger C, et al. Canadian normative data for the SF-36 health survey. 2000; 163(3):265-71.

39. Ford ES, Li CJA. Metabolic syndrome and health-related quality of life among US adults. 2008;18(3):165-71.

40. Mahambetalieva N, Mershenova G, Seytekova A, Zhumabekova I, Mirzaeva BJG. Evaluation of quality of life in patients with metabolic syndrome. 2018; 274:107-12.

41. Saboya PP, Bodanese LC, Zimmermann PR, Gustavo AS, Assumpção CM, Londero FJRI-a. Metabolic syndrome and quality of life: a systematic review. 2016;24.

42. Corina A, Abrudan MB, Nikolic D, Cătoi AF, Chianetta R, Castellino G, et al, Effects of Aging and Diet on Cardioprotection and Cardiometabolic Risk Markers. Curr Pharm Des. 2019;25(35):3704-14.

43. Aebi NJ, Bringolf-Isler B, Schaffner E, Caviezel S, Imboden M, Probst-Hensch NJSMW. Patterns of cross-sectional and predictive physical activity in Swiss adults aged 52+: results from the SAPALDIA cohort. 2020;150(2526).

44. BFS. BfS. Schweizerische Gesundheitsbefragung 2017 Körperliche Aktivität und Gesundheit

45. Bouaziz W, Vogel T, Schmitt E, Kaltenbach G, Geny B, Lang POJA, et al. Health benefits of aerobic training programs in adults aged 70 and over: a systematic review. 2017;69:110-27.

46. Pengpid S, Peltzer KJCP. High sedentary behaviour and low physical activity are associated with lower health related quality of life in Myanmar and Vietnam. 2019;6(1):1601327

47. Fanning J, Walkup MP, Ambrosius WT, Brawley LR, Ip EH, Marsh AP, et al. Change in health-related quality of life and social cognitive outcomes in obese, older adults in a randomized controlled weight loss trial: Does physical activity behavior matter? J Behav Med. 2018;41(3):299-308.

48. van Namen M, Prendergast $L$, Peiris C. Supervised lifestyle intervention for people with metabolic syndrome improves outcomes and reduces individual risk factors of metabolic syndrome: A systematic review and meta-analysis. Metab Clin Exp. 2019;101:153988.

49. Dieli-Conwright CM, Courneya KS, Demark-Wahnefried W, Sami N, Lee K, Sweeney FC, et al. Aerobic and resistance exercise improves physical fitness, bone health, and quality of life in overweight and obese breast cancer survivors: a randomized controlled trial. Breast Cancer Res. 2018;20(1):124.

50. Booth FW, Roberts CK, Laye MJ. Lack of exercise is a major cause of chronic diseases. Compr Physiol. 2012;2(2):1143-211.

51. Myers J, Kokkinos P, Nyelin E. Physical Activity, Cardiorespiratory Fitness, and the Metabolic Syndrome. Nutrients. 2019;11(7).

52. Mattli R, Farcher R, Syleouni ME, Wieser S, Probst-Hensch N, SchmidtTrucksäss A, et al. Physical Activity Interventions for Primary Prevention in Adults: A Systematic Review of Randomized Controlled Trial-Based Economic Evaluations. Sports Med (Auckland, NZ). 2020;50(4):731-50.

53. Kolotkin RL, Andersen JRJC. A systematic review of reviews: exploring the relationship between obesity, weight loss and health-related quality of life. 2017;7(5):273-89.

54. Atif M, Saleem Q, Babar Z-U-D, Scahill SJM. Association between the Vicious Cycle of Diabetes-Associated Complications and Glycemic Control among the Elderly: A Systematic Review. 2018;54(5):73.
55. Cobo A, Vázquez LA, Reviriego J, Rodríguez-Mañas LJEN. Impact of frailty in older patients with diabetes mellitus: An overview. 2016;63(6):291-303.

56. Ball K, Carver A, Downing K, Jackson M, O'Rourke KJH. Addressing the social determinants of inequities in physical activity and sedentary behaviours. 2015;30(suppl_2):ii8-ii19.

57. Bonaccio M, lacoviello L, De Gaetano G, research M-SIJT. The Mediterranean diet: the reasons for a success. 2012;129(3):401-4.

58. Livingston MJD, review a. Socioeconomic differences in alcohol-related risktaking behaviours. 2014;33(6):588-95

59. Newton S, Braithwaite D, Akinyemiju TFJP. Socio-economic status over the life course and obesity: Systematic review and meta-analysis. 2017;12(5): e0177151.

60. Prince S, Reed J, McFetridge C, Tremblay M, Reid RJO. Correlates of sedentary behaviour in adults: a systematic review. 2017;18(8):915-35.

61. Thebault J-L, Ringa V, Panjo H, Bloy G, Falcoff H, Rigal LP. Accumulation of unhealthy behaviors: Marked social inequalities in men and women. 2018; 12:1-5.

62. Volaco A, Cavalcanti AM, Roberto Filho P, Précoma DBJC. Socioeconomic status: the missing link between obesity and diabetes mellitus? 2018;14(4): 321-6.

63. Alkerwi A, Donneau A-F, Sauvageot N, Lair M-L, Albert A, Guillaume MJP. Dietary, behavioural and socio-economic determinants of the metabolic syndrome among adults in Luxembourg: findings from the ORISCAV-LUX study. 2012;15(5):849-59.

64. Pucci G, Alcidi R, Tap L, Battista F, Mattace-Raso F, Schillaci GJP. Sex-and gender-related prevalence, cardiovascular risk and therapeutic approach in metabolic syndrome: A review of the literature. 2017;120:34-42.

65. Santos AC, Ebrahim S, Barros HJBPH. Gender, socio-economic status and metabolic syndrome in middle-aged and old adults. 2008;8(1):62.

66. Read $\mathrm{S}$, Grundy E, Foverskov EJA, health $\mathrm{m}$. Socio-economic position and subjective health and well-being among older people in Europe: a systematic narrative review. 2016;20(5):529-42.

67. Stojanović M, Cvetanović G, Anđelković-Apostolović M, Stojanović D, Rančić NJCE. Impact of Socio-Demographic Characteristics and Long-Term Complications on Quality of Life in Patients with Diabetes Mellitus. 2018; 26(2):104-10.

68. Berset A, Grimaldi L, Kiefer BJR. Prevention: how can Switzerland make up the delay? 2015;11(491):1932-5

69. Goettler A, Grosse A, Sonntag DJB. Productivity loss due to overweight and obesity: a systematic review of indirect costs. 2017;7(10):e014632.

70. Hämmig O, Bauer GFJB. The social gradient in work and health: a crosssectional study exploring the relationship between working conditions and health inequalities. 2013;13(1):1170.

\section{Publisher's Note}

Springer Nature remains neutral with regard to jurisdictional claims in published maps and institutional affiliations.

Ready to submit your research? Choose BMC and benefit from:

- fast, convenient online submission

- thorough peer review by experienced researchers in your field

- rapid publication on acceptance

- support for research data, including large and complex data types

- gold Open Access which fosters wider collaboration and increased citations

- maximum visibility for your research: over $100 \mathrm{M}$ website views per year

At $\mathrm{BMC}$, research is always in progress.

Learn more biomedcentral.com/submissions 